\title{
TeleMedicine/TelePsychiatry in Nepal
}

\author{
Thapa DK', Subedi S²
}

1. Associate Professor, Dept. Of Psychiatry, GMC, Pokhara, Nepal 2. Associate Professor, Dept. Of Psychiatry, UCMS, Bhairahawa, Nepal

E-mail *Corresponding author: ddthapa@hotmail.com

\section{INTRODUCTION:}

The advancing information and communication technologies are revolutionizing our methods of communication and seeking and exchanging of information. ${ }^{1}$ Almost every aspect of our lives is influenced by technologies; be it in education, banking, shopping, travelling etc. These technologies have great potential to help address contemporary global health problems too. ${ }^{1}$

Telemedicine, a term coined in the 1970s, literally means "healing at a distance". ${ }^{2}$ Though there is no one definitive definition of telemedicine ${ }^{3}$, the World Health Organization has adopted the following broad description:

"The delivery of health care services, where distance is a critical factor, by all health care professionals using information and communication technologies for the exchange of valid information for diagnosis, treatment and prevention of disease and injuries, research and evaluation, and for the continuing education of health care providers, all in the interests of advancing the health of individuals and their communities". 4

Though telemedicine is an open and constantly evolving science that responds and adapts to the changing health needs and contexts of societies by incorporating new advancements in technology, four elements are germane to telemedicine:

1. Its purpose is to provide clinical support.
2. It is intended to overcome geographical barriers, connecting users who are not in the

3. same physical location.

4. It involves the use of various types of information and communication technologies.

5. Its goal is to improve health outcomes.

Telepsychiatry is a subset of telemedicine that can involve providing a range of services including psychiatry evaluations therapy( individual therapy, group therapy, family therapy), patient education and education management. It can involve direct interaction between a psychiatrist and the patient. Telepsychiatry is considered as the most active application of telemedicine in the western world. However, in developing countries like ours, telepsychiatry is still in infancy.

\section{TELEMEDICINE / TELEPSYCHIATRY IN NEPAL}

The majority of telemedicine services, most of which focus on diagnosis and clinical management, are routinely countries like United Kingdom of Great Britain and Northern Ireland, Scandinavia, North America, and Australia.5,6 The literature reports that though telemedicine offers great opportunities in general, it could be even more beneficial for underserved and developing countries where access to basic care is of primary concern. One of the biggest opportunities telemedicine presents is increased access to health care. Providing populations in 
these underserved countries with the means to access health care has the potential to help meet previously unmet needs 7 and positively impact health services. ${ }^{8}$

Needless to say that the telemedicine/Telepsychiatry provides opportunities for learning and professional development by enabling the provision and dissemination of general information, it is very crucial for developing countries like Nepal for several reasons.

Majority of Nepalese people live in the rural area and are economically not sound. They lack accessibility to the better health care system and proper healthy living condition. Owing to the remoteness and the poor travel system in the country the transport of the needy patients are difficult. In that aspect reaching out to those in needs in the form of telemedicine cut short the distance and hurdles between the health care providers and the sick.

Since the country lacks the adequate numbers of experts and specialists, telepsychiatry can fill up that lacuna by reaching out to those in isolated communities and remote without the patient having to travel to visit them.

Advancing information and communication technologies allow remote patient monitoring leading to reduction in the need for frequent outpatient visits and enable remote prescription verification and drug administration, potentially significantly reducing the financial burden.

The drawbacks of telemedicine/telepsychiatry are several. They include the cost of telecommunication and data management and technical training for medical personnel, decreased human interaction between medical professionals and patients, increased risk of error when medical services are delivered in the absence of a registered professional, compromise of patient's privacy etc.

\section{REFERENCES:}

1. http://www.who.int/goe/publications/goe_tel emedicine_2010.pdf

2. Strehle EM, Shabde N. One hundred years of telemedicine: does this new technology have a place in paediatrics? Archives of Disease in Childhood, 2006, 91(12):956-959.

3. Sood SP, et al. Differences in public and private sector adoption of telemedicine: Indian case study for sectoral adoption. Studies in Health Technology and Informatics, 2007, 130:257-268.
4. WHO. A health telematics policy in support of WHO's Health-For-All strategy for global health development: report of the WHO group consultation on health telematics, 11-16 December, Geneva, 1997. Geneva, World Health Organization, 1998.

5. Craig J, Patterson V. Introduction to the practice of telemedicine. Journal of Telemedicine and Telecare, 2005, 11(1):3-9.

6. Wootton R. The development of telemedicine. In: Rigby, Roberts, Thick, eds. Taking Health Telematics into the 21st Century. Oxon, Radcliffe Medical Press, 2000:17-26.

7. Brandling-Bennett HA et al. Delivering health care in rural Cambodia via store-and-forward telemedicine: a pilot study. Telemedicine Journal and e-Health, 2005, 11(1):56-62.

8. Pradhan MR. ICTs application for better health in Nepal. Kathmandu University Medical Journal, 2004, 2(2):157-163. 